\title{
ON OPERATION CAPABILITIES ANALYSIS OF A 100000 TDW TANKER BY SEAKEEPING CRITERIA
}

\author{
Leonard Domnișoru \\ "Dunarea de Jos" University of Galati, \\ Faculty of Naval Architecture, \\ Galati, Domneasca Street, No. 47, 800008, Romania, \\ E-mail: leonard.domnisoru@ugal.ro
}

\begin{abstract}
The operation capabilities of a maritime ship have to be assessed during the design, including the seakeeping criteria. In this study a $100000 \mathrm{tdw}$ tanker is considered, with two loading conditions, cargo and ballast. The numerical analyses are developed with our own software DYN, module OSC, based on a linear hydrodynamic strip theory. The main oscillation components, heave, pitch and roll, are considered. The analysis includes an extended parametric study for the tanker speed up to 15 knots, different vertical positions of the gravity centre, a heading angle full range and irregular waves significant height up to $12 \mathrm{~m}$. Also the seakeeping limits have two sets of criteria. The results are pointing out the operation limits of the tanker on combined navigation parameters in irregular waves, by motions and acceleration short term seakeeping criteria.
\end{abstract}

Keywords: ship oscillations, tanker ship, irregular waves, seakeeping criteria, parametric study.

\section{INTRODUCTION}

The development of the design concept for a maritime ship involves many criteria to be assessed, according to the design rules of the ship's classification societies [4],[5],[13].

In this study the seakeeping analysis [1], [2],[10],[11],[14] is selected, for an extended parametric study of the operation capabilities evaluation of a 100000 tdw tanker [8].

The following main parameters are considered: loading case $\Delta, x_{G}$, cargo (TK1) and ballast (TK2); speed $v, 0,5,10,12.5$, and 15 $\mathrm{kn}$; the theoretical vertical position of the gravity centre $z_{G}, 8,9,10,11,12,13$ and 14 $\mathrm{m}$; tanker-wave heading angle $\mu, 0-360 \mathrm{deg}$, step $5 \mathrm{deg}$; irregular waves significant height $H_{s}, 0-12 \mathrm{~m}$, step $0.05 \mathrm{~m}$. In addition, two sets of limit values for the seakeeping criteria are considered.

The study ship, a 100000 tdw tanker [8], has the transversal offset-lines illustrated in Fig.1 and the main characteristics shown in Table 1.
Figs.2.a,b and Tables 2.,b present the transversal stability data and the natural periods for roll oscillations, for the $z_{G}$ theoretical range.

The seakeeping simulations are done by our own program DYN [6], module OSC, for ship's oscillations in regular and irregular waves, statistical short-term results, based on a linear strip theory hydrodynamic model, presented in brief in section 2. The program DYN-OSC has been previously validated by several experimental tests on scaled models, at towing tank, in regular head, follow and beam wave conditions, with the results presented in references [3],[7],[9],[12]. The parametric study aims to test the sensitivity of the operation limits of the 100000 tdw tank, due to the changes of several navigation data.

The dynamic response in regular waves of the 100000 tdw tankers, in terms of the response amplitude operators [1],[14], is presented in section 3. The dynamic response in irregular waves and seakeeping criteria assessment [6],[11] are presented in section 4. 
The conclusions of this study (section 5) synthesize the 100000 tdw tanker operation limits parametric study by seakeeping criteria.

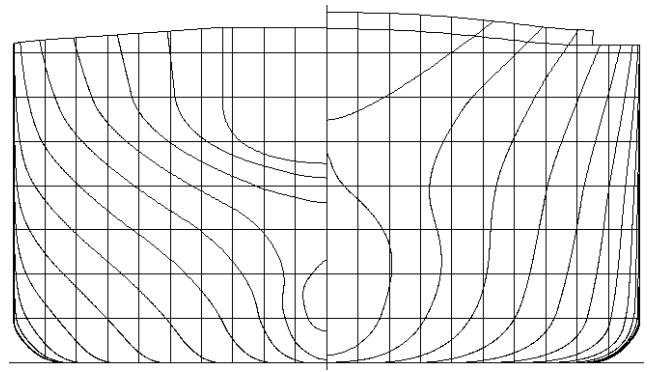

Fig.1.The 100000 tdw tank offset-lines [8]

Table 1. The 100000 tdw tank main data [8]

\begin{tabular}{|c|c|c|c|c|}
\hline$L_{O A}[\mathrm{~m}]$ & 246 & Case: & TK1cargo & TK2ballast \\
\hline$B[\mathrm{~m}]$ & 42 & $\Delta[\mathrm{t}]$ & 126457 & 81763 \\
\hline$H[\mathrm{~m}]$ & 21.3 & $x_{G}[\mathrm{~m}]$ & 126.4 & 128.3 \\
\hline$\rho\left[\mathrm{t} / \mathrm{m}^{3}\right]$ & 1.025 & $L_{W L}[\mathrm{~m}]$ & 240 & 232 \\
\hline$g\left[\mathrm{~m} / \mathrm{s}^{2}\right]$ & 9.81 & $d_{m}[\mathrm{~m}]$ & 15 & 10 \\
\hline$H_{\text {smax }}[\mathrm{m}]$ & 12 & $T_{3}[\mathrm{~s}]$ & 10.333 & 9.336 \\
\hline stations & 41 & $T_{5}[\mathrm{~s}]$ & 10.517 & 9.796 \\
\hline points & 1230 & $z_{G}[\mathrm{~m}]$ & \multicolumn{2}{|c|}{$8-14$ (step 1) } \\
\hline$v_{\max }[\mathrm{kn}]$ & 15 & $\mu[\mathrm{deg}]$ & \multicolumn{3}{|c}{$0-360($ step 5) } \\
\hline
\end{tabular}

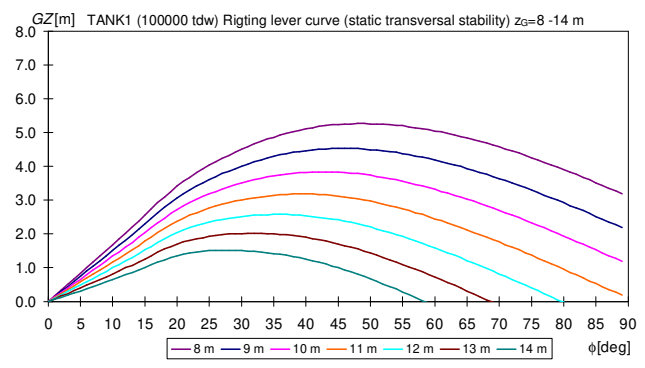

Fig.2.a. $G Z[\mathrm{~m}], \mathrm{TK} 1, d_{m}=15 \mathrm{~m}, z_{G}=8-14 \mathrm{~m}$

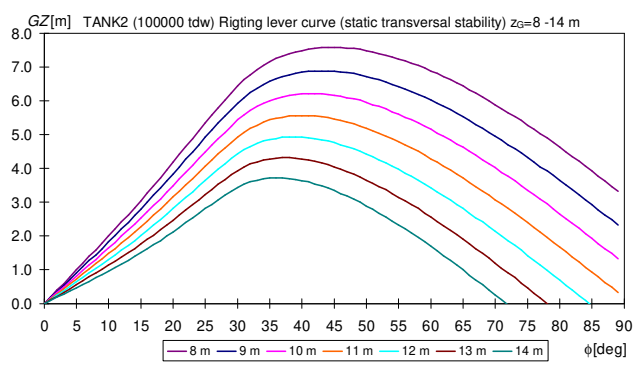

Fig.2.b. $G Z[\mathrm{~m}]$, TK $2, d_{m}=10 \mathrm{~m}, z_{G}=8-14 \mathrm{~m}$
Table 2.a TK1, stability data and roll periods

\begin{tabular}{|c|c|c|c|c|}
\hline$z_{G}[\mathrm{~m}]$ & $G M_{T O}[\mathrm{~m}]$ & $J_{x}\left[\mathrm{tm}^{2}\right]$ & $T_{4}[\mathrm{~s}]$ & $\varphi_{\max G Z}[\mathrm{deg}]$ \\
\hline 8 & 9.562 & 21286956 & 9.631 & 49 \\
\hline 9 & 8.562 & 22003546 & 10.334 & 46 \\
\hline 10 & 7.562 & 22804441 & 11.181 & 43 \\
\hline 11 & 6.562 & 23689642 & 12.233 & 39 \\
\hline 12 & 5.562 & 24659147 & 13.547 & 36 \\
\hline 13 & 4.562 & 25712956 & 15.255 & 32 \\
\hline 14 & 3.562 & 26851071 & 17.564 & 28 \\
\hline
\end{tabular}

Table 2.b TK2, stability data and roll periods

\begin{tabular}{|c|c|c|c|c|}
\hline$z_{G}[\mathrm{~m}]$ & $G M_{T 0}[\mathrm{~m}]$ & $J_{x}\left[\mathrm{tm}^{2}\right]$ & $T_{4}[\mathrm{~s}]$ & $\varphi_{\max G Z}[\mathrm{deg}]$ \\
\hline 8 & 11.303 & 13763496 & 10.468 & 45 \\
\hline 9 & 10.303 & 14226821 & 11.223 & 43 \\
\hline 10 & 9.303 & 14744656 & 12.074 & 41 \\
\hline 11 & 8.303 & 15316999 & 13.005 & 40 \\
\hline 12 & 7.303 & 15943851 & 14.018 & 39 \\
\hline 13 & 6.303 & 16625213 & 15.265 & 37 \\
\hline 14 & 5.303 & 17361083 & 16.846 & 36 \\
\hline
\end{tabular}

\section{THEORETICAL FUNDAMENTS}

The seakeeping analysis with our own program DYN [6], module OSC, based on a linear strip theory 2D hydrodynamic model [2],[6],[14], has three main steps.

- Dynamic response in regular waves, when the response amplitude operators $R A O$ are obtained by a direct solution in the frequency domain of the motions equations system:

$[A]\{\ddot{p}(t)\}+[B]\{\dot{p}(t)\}+[C]\{p(t)\}=\left\{E_{w}(t)\right\}$ $\left\{E_{w}(t)\right\}=\left\{E_{w}^{c}\right\} \cos \omega_{e} t+\left\{E_{w}^{s}\right\} \sin \omega_{e} t \rightarrow$

$p_{j}(t)=p_{j}^{c} \cos \omega_{e} t+p_{j}^{s} \sin \omega_{e} t j=3,4,5$

$p_{j}^{a}=\sqrt{\left(p_{j}^{c}\right)^{2}+\left(p_{j}^{s}\right)^{2}} ; \omega_{e}=\omega-\frac{\omega^{2}}{g} v \cos \mu$

$R A O_{j}\left(\omega_{e}\right)=\left.p_{j}^{a}\left(\omega_{e}\right)\right|_{a w=1} j=3,4,5$

where: $[A],[B],[C]$ are the radiation matrix; $\left\{E_{w}(t)\right\}$ is the regular wave diffraction vector; $\{p(t)\}$ is the dynamic response; $\omega_{e}$ is the wave encountering frequency; $\omega, \mu$ are the regular wave frequency and heading angle; $v$ is the ship speed; $R A O_{j}\left(\omega_{e}\right) j=3,4,5$ are the heave, roll and pitch $R A O$ functions. 
- Dynamic response in irregular waves, when the most probable short-term statistical motions $R M S_{j}$ (5) and acceleration $R M S_{a c j}$ (6) amplitudes are obtained:

$$
\begin{aligned}
& S_{j}\left(\omega_{e}\right)=R A O_{j}^{2}\left(\omega_{e}\right) S_{w}\left(\omega_{e}\right) j=3,4,5 \\
& R M S_{j}=\left(\int_{\left(\omega_{e}\right)} S_{j}\left(\omega_{e}\right) d \omega_{e}\right)^{0.5} j=3,4,5 \\
& R M S_{a c j}=\left(\int_{\left(\omega_{e}\right)} \omega_{e}^{4} S_{j}\left(\omega_{e}\right) d \omega_{e}\right)^{0.5} j=3,4,5
\end{aligned}
$$

where: $S_{w}$ is the wave power density spectrum, ITTC [10] (Fig.9); $S_{j}$ is the response spectrum.

- The polar diagrams of wave height significant and Beaufort level limits (7) by seakeeping criteria (8) - (11) are obtained, with two sets of admissible values from Table 3 :

$$
\begin{aligned}
& H_{s \lim }(\Delta, v, \mu) ; B_{\lim }(\Delta, v, \mu) \\
& R M S_{Z}=R M S_{3}+\xi_{\text {amf }} R M S_{5}+\frac{B}{2} R M S_{4}+\frac{H_{s}}{4} \\
& \xi_{\text {aft }}=x_{F} ; \xi_{\text {mid }}=0 ; \xi_{\text {fore }}=L-x_{F} \\
& R M S_{\text {zadm }}=H-f_{s}-\left.d\right|_{\text {aft, mid }, \text { fore }} f_{s}=0.3 \mathrm{~m} \\
& R M S_{Z} \leq R M S_{\text {Zadm }} \mid \text { aft,mid, fore } \\
& R M S_{a c 3} \leq R M S_{a c 3 a d m}=0.1 \mathrm{~g} \\
& R M S_{4} \leq R M S_{4 a d m}=6-8 \mathrm{deg} \\
& R M S_{a c 4} \leq R M S_{a c 4 a d m}=0.15 \mathrm{~g} /(B / 2) \\
& R M S_{5} \leq R M S_{5 a d m}=3-4 \mathrm{deg} \\
& R M S_{a c 5} \leq R M S_{a c 5 a d m}=0.15 \mathrm{~g} / \mathrm{min}\left\{\xi_{a f t}, \boldsymbol{\xi}_{\text {fore }}\right\}
\end{aligned}
$$

where: $x_{F}$ is the reference still water plane centre longitudinal position $(x=0, L)$.

Table 3 Seakeeping criteria admissible values

\begin{tabular}{|l|c|c|}
\hline Limits version & Criteria A & Criteria B \\
\hline$R M S_{\text {Zaft adm }}[\mathrm{m}]$ & 7.3 & 7.8 \\
\hline$R M S_{\text {Zmid adm }}[\mathrm{m}]$ & 6.0 & 6.5 \\
\hline$R M S_{\text {Zfore adm }}[\mathrm{m}]$ & 7.7 & 8.2 \\
\hline$R M S_{5 \text { adm }}[\mathrm{rad}]$ & 0.05236 & 0.06981 \\
\hline$R M S_{4 \text { adm }}[\mathrm{rad}]$ & 0.10472 & 0.13963 \\
\hline$R M S_{\text {ac } 3 \text { adm }}\left[\mathrm{m} / \mathrm{s}^{2}\right]$ & 0.981 & 0.981 \\
\hline$R M S_{\text {ac } 5 \text { adm }}\left[\mathrm{rad} / \mathrm{s}^{2}\right]$ & 0.01224 & 0.01224 \\
\hline$R M S_{\text {ac } 4 \text { adm }}\left[\mathrm{rad} / \mathrm{s}^{2}\right]$ & 0.07007 & 0.07007 \\
\hline
\end{tabular}

\section{DYNAMIC RESPONSE IN REGULAR WAVES}

The dynamic response in regular waves is computed for a wave frequency range of $\omega=0-3 \mathrm{rad} / \mathrm{s}$, step $0.001 \mathrm{rad} / \mathrm{s}$ and wave amplitude $a_{w}=1 \mathrm{~m}$, covering the whole oscillations range frequencies of heave, pitch and roll motions. Using equations (1)-(3), the $R A O$ response amplitude operators are obtained by DYN [6], module OSC, for the parametric study defined in section 1 .

\subsection{Loading case TK1}

Figs.3.a-d present a selection of heave $\mathrm{RAO}_{3}$ for the loading case TK1. The maximum heave results are at at head-quarter wave, $\mu=135 \mathrm{deg}$ (Fig.3.a). The influence of the ship's speed for heave response is on $\omega=0.5-1.25 \mathrm{rad} / \mathrm{s}$ at follow wave (Fig.3.b); it is negligible at beam wave (Fig.3.c) and is on $\omega=0.25-1 \mathrm{rad} / \mathrm{s}$ at head wave (Fig.3.d).

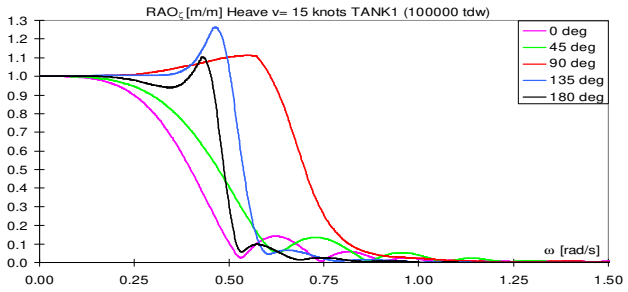

Fig.3.a. $R A O_{3}[\mathrm{~m} / \mathrm{m}], \mathrm{TK} 1, d_{m}=15 \mathrm{~m}, v=15 \mathrm{kn}$

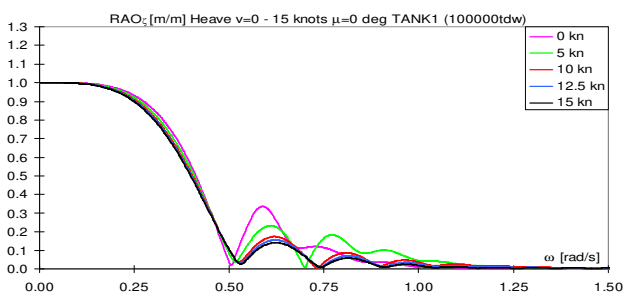

Fig.3.b. $R A O_{3}[\mathrm{~m} / \mathrm{m}], \mathrm{TK} 1, \mu=0 \mathrm{deg}, v=0-15 \mathrm{kn}$

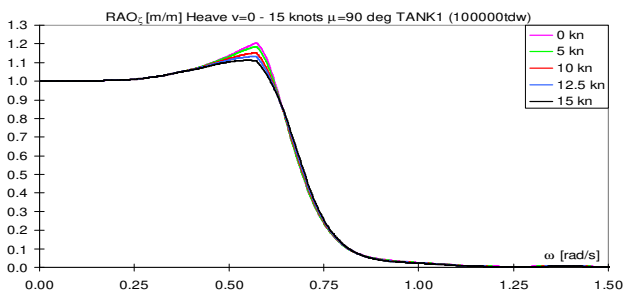

Fig.3.c. $R A O_{3}[\mathrm{~m} / \mathrm{m}], \mathrm{TK} 1, \mu=90 \mathrm{deg}, \nu=0-15 \mathrm{kn}$ 


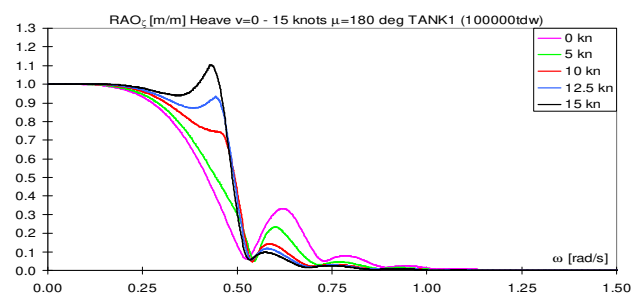

Fig.3.d. $R A O_{3}[\mathrm{~m} / \mathrm{m}], \mathrm{TK} 1, \mu=180 \mathrm{deg}, v=0-15 \mathrm{kn}$

Figs.4.a-d present a selection of pitch $R A O_{5}$ for the loading case TK1. The maximum pitch results at head wave, and is very reduced at beam wave (Figs.4.a,c). The influence of the ship's speed for pitch response is on $\omega=0.25$ $1.25 \mathrm{rad} / \mathrm{s}$ at follow and head waves (Figs.4.b,d).

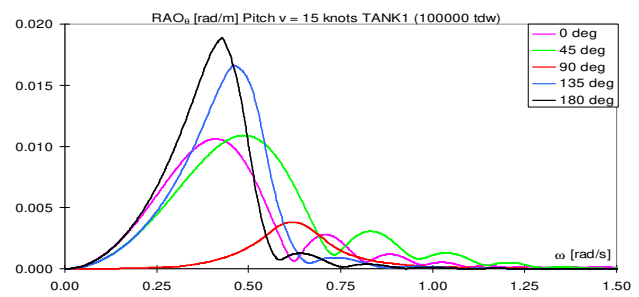

Fig.4.a. $R A O_{5}[\mathrm{rad} / \mathrm{m}], \mathrm{TK} 1, d_{m}=15 \mathrm{~m}, v=15 \mathrm{kn}$

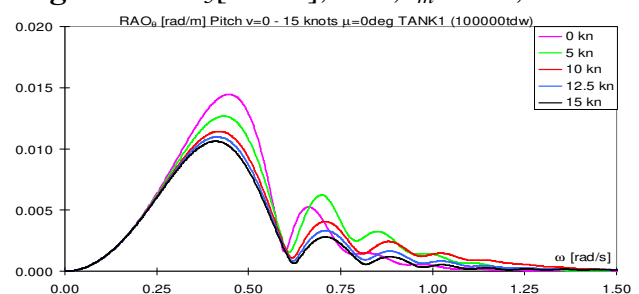

Fig.4.b. $R A O_{5}[\mathrm{rad} / \mathrm{m}], \mathrm{TK} 1, \mu=0 \mathrm{deg}, v=0-15 \mathrm{kn}$

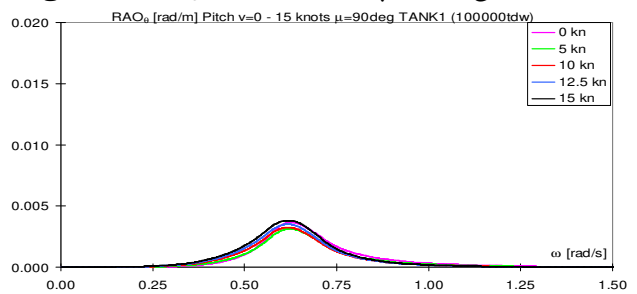

Fig.4.c. $R A O_{5}[\mathrm{rad} / \mathrm{m}], \mathrm{TK} 1, \mu=90 \mathrm{deg}, \nu=0-15 \mathrm{kn}$

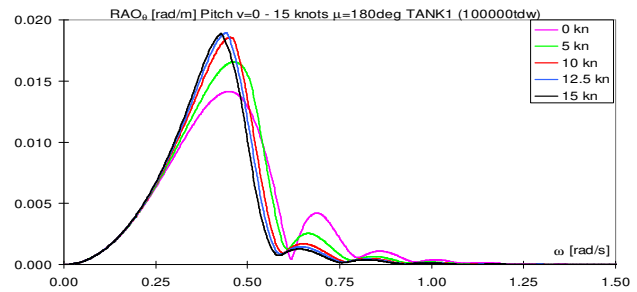

Fig.4.d. $R A O_{5}[\mathrm{rad} / \mathrm{m}], \mathrm{TK} 1, \mu=180 \mathrm{deg}, \nu=0-15 \mathrm{kn}$
Figs.5.a-d present a selection of roll $\mathrm{RAO}_{4}$ for the loading case TK1. The maximum roll results at beam wave (Figs.5.a,b,c); it is smaller at quartering wave and zero at follow and head wave. The influence of the ship's speed for roll response is on $\omega=0.25-0.75 \mathrm{rad} / \mathrm{s}$ at aft and fore quarter waves (Figs.5.b,c); it is negligible at beam wave. Due to the significant changes of the natural roll period function to the vertical position of the gravity centre $z_{G}=8-14 \mathrm{~m}$ (Table 2.a), $T_{4}=9.631-17.564 \mathrm{~s}\left(\omega_{4}=0.652-0.358 \mathrm{rad} / \mathrm{s}\right)$, the maximum roll $\mathrm{RAO}_{4}(\mu=90)$ is for $z_{G}=8 \mathrm{~m}$ (Figs.5.d), due to the fact that the roll hydrodynamic damping decreases when the frequency increases [6],[14].

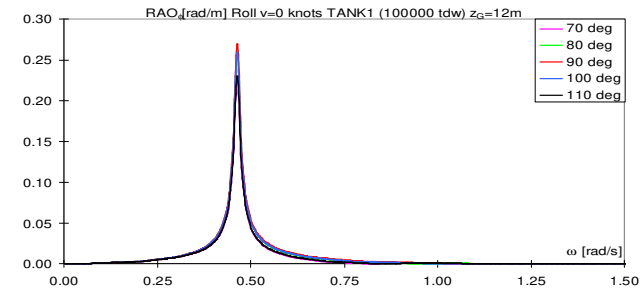

Fig.5.a. $R A O_{4}[\mathrm{rad} / \mathrm{m}], \mathrm{TK} 1, z_{G}=12 \mathrm{~m}, v=0 \mathrm{kn}$

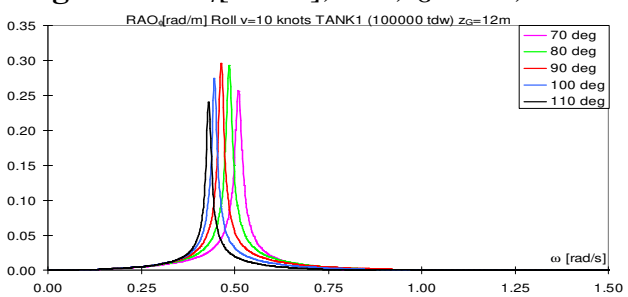

Fig.5.b. $\mathrm{RAO}_{4}[\mathrm{rad} / \mathrm{m}], \mathrm{TK} 1, z_{G}=12 \mathrm{~m}, v=10 \mathrm{kn}$

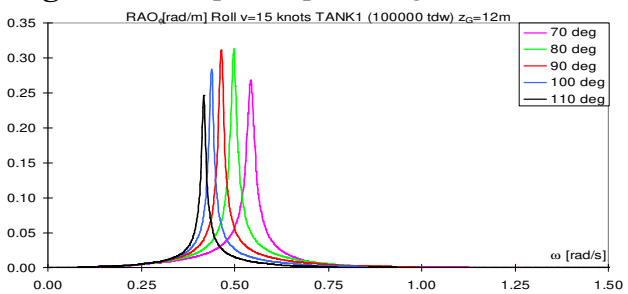

Fig.5.c. $R A O_{4}[\mathrm{rad} / \mathrm{m}], \mathrm{TK} 1, z_{G}=12 \mathrm{~m}, v=15 \mathrm{kn}$

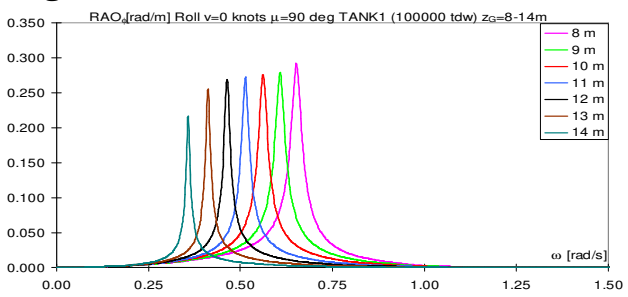

Fig.5.d. $\mathrm{RAO}_{4}, \mathrm{TK} 1, \mu=90, z_{G}=8-14 \mathrm{~m}, \nu=0 \mathrm{kn}$ 


\subsection{Loading case TK2}

Figs.6.a-d present a selection of heave $\mathrm{RAO}_{3}$ for the loading case TK2. The maximum heave results at beam wave (Fig.6.a). The influence of the ship's speed for heave response is on $\omega=0.55-1.3 \mathrm{rad} / \mathrm{s}$ at follow wave (Fig.6.b); it is negligible at beam wave (Fig.6.c) and is on $\omega=0.1-1.25 \mathrm{rad} / \mathrm{s}$ at head wave (Fig.6.d).

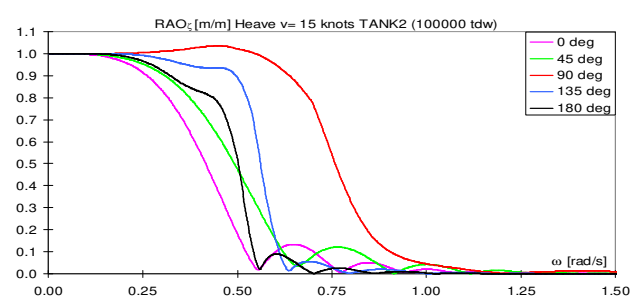

Fig.6.a. $R A O_{3}[\mathrm{~m} / \mathrm{m}], \mathrm{TK} 2, d_{m}=10 \mathrm{~m}, v=15 \mathrm{kn}$

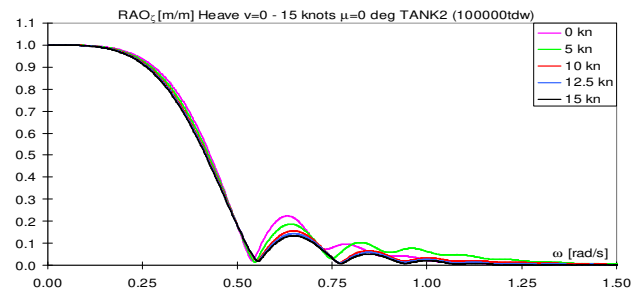

Fig.6.b. $\mathrm{RAO}_{3}[\mathrm{~m} / \mathrm{m}], \mathrm{TK} 2, \mu=0 \mathrm{deg}, \nu=0-15 \mathrm{kn}$

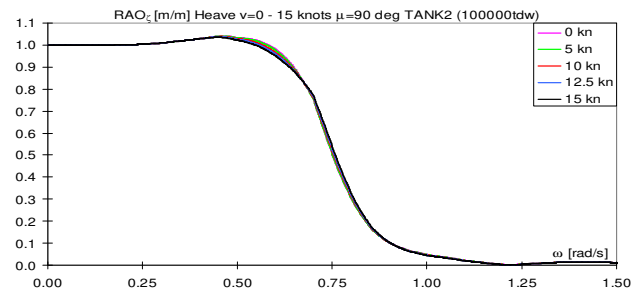

Fig.6.c. $R \mathrm{AO}_{3}[\mathrm{~m} / \mathrm{m}], \mathrm{TK} 2, \mu=90 \mathrm{deg}, \nu=0-15 \mathrm{kn}$

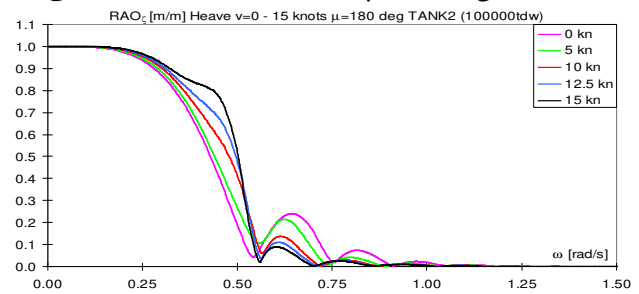

Fig.6.d. $R A O_{3}[\mathrm{~m} / \mathrm{m}], \mathrm{TK} 2, \mu=180 \mathrm{deg}, \nu=0-15 \mathrm{kn}$

Figs.7.a-d present a selection of pitch $R A O_{5}$ for the loading case TK2. The maximum pitch results at head wave and is very reduced at beam wave (Figs.7.a,c). The influence of the ship's speed for pitch response is on $\omega=0.2-1.3$ $\mathrm{rad} / \mathrm{s}$ at follow and head wave (Figs.7.b,d).

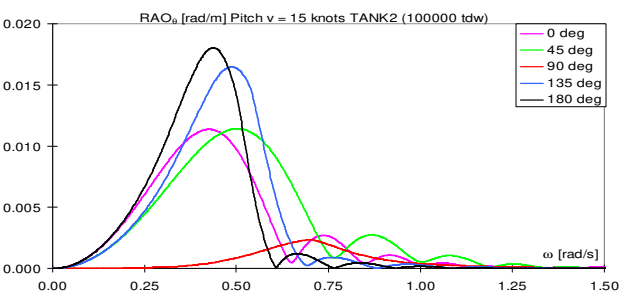

Fig.7.a. $R A O_{5}[\mathrm{rad} / \mathrm{m}], \mathrm{TK} 2, d_{m}=10 \mathrm{~m}, v=15 \mathrm{kn}$

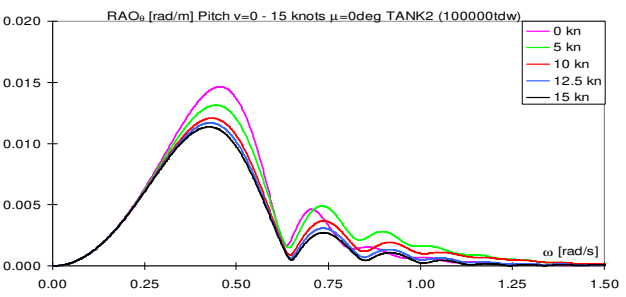

Fig.7.b. $R A O_{5}[\mathrm{rad} / \mathrm{m}], \mathrm{TK} 2, \mu=0 \mathrm{deg}, v=0-15 \mathrm{kn}$

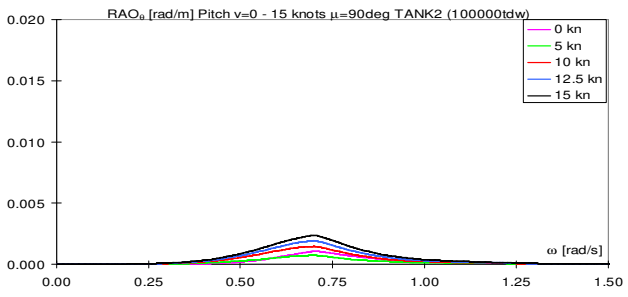

Fig.7.c. $R A O_{5}[\mathrm{rad} / \mathrm{m}], \mathrm{TK} 2, \mu=90 \mathrm{deg}, \nu=0-15 \mathrm{kn}$

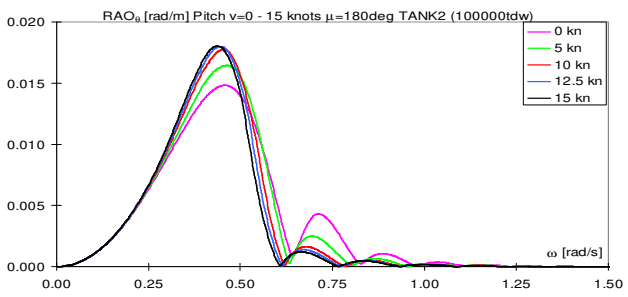

Fig.7.d. $R A O_{5}[\mathrm{rad} / \mathrm{m}], \mathrm{TK} 2, \mu=180 \mathrm{deg}, \nu=0-15 \mathrm{kn}$

Figs.8.a-d present a selection of roll $\mathrm{RAO}_{4}$ for the loading case TK2. The maximum roll results at beam wave (Figs.8.a,b,c); it is zero at follow and head wave. In comparison to case TK1 (Figs.5.a,b,c), in this case the roll response has a wider frequency band. The influence of the ship's speed for roll response is on $\omega=0.25$ $1.25 \mathrm{rad} / \mathrm{s}$ at quarter waves (Figs.8.b,c) and is negligible at beam wave. Analogously to case TK1, the natural roll period changes for $z_{G}=8$ $14 \mathrm{~m}$ (Table 2.b), $T_{4}=10.468-16.846 \mathrm{~s}$ $\left(\omega_{4}=0.600-0.373 \mathrm{rad} / \mathrm{s}\right)$, so that the maximum roll $\mathrm{RAO}_{4}(\mu=90)$ is for $z_{G}=8 \mathrm{~m}$ (Fig.8.d), being significantly smaller for $z_{G}=14$. 


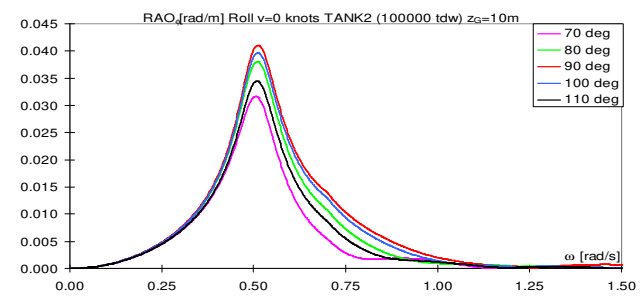

Fig.8.a. $R A O_{4}[\mathrm{rad} / \mathrm{m}], \mathrm{TK} 2, z_{G}=10 \mathrm{~m}, v=0 \mathrm{kn}$

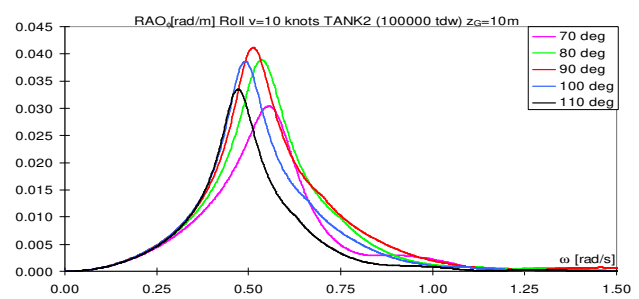

Fig.8.b. $R A O_{4}[\mathrm{rad} / \mathrm{m}], \mathrm{TK} 2, z_{G}=10 \mathrm{~m}, v=10 \mathrm{kn}$

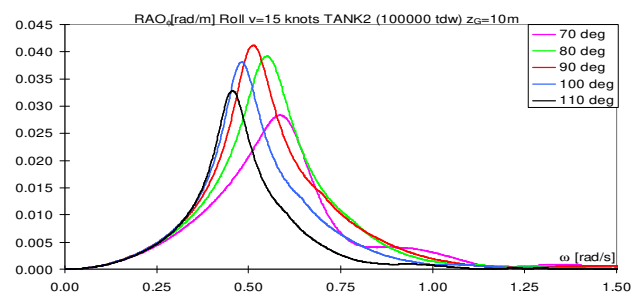

Fig.8.c. $R A O_{4}[\mathrm{rad} / \mathrm{m}], \mathrm{TK} 2, z_{G}=10 \mathrm{~m}, v=15 \mathrm{kn}$

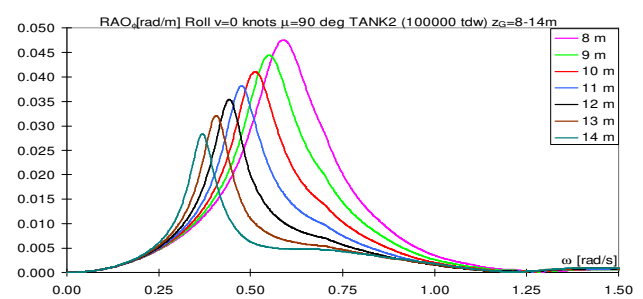

Fig.8.d. $R A O_{4}, \mathrm{TK} 2, \mu=90, z_{G}=8-14 \mathrm{~m}, v=0 \mathrm{kn}$

\section{DYNAMIC RESPONSE IN IRREGULAR WAVES}

The dynamic response in irregular waves is computed using the $R A O$ functions from section 3 and the ITTC wave power density spectrum from Fig.9 [10], for an unrestricted navigation condition $H_{\text {smax }}=12 \mathrm{~m}$. Using equations (4)-(6), the $R M S$ most probable amplitudes for heave, pitch, roll, motions and accelerations are obtained by DYN [6], module OSC. Based on the seakeeping criteria from equations (8)-(11), the polar diagrams for navigation safety (7) are obtained.

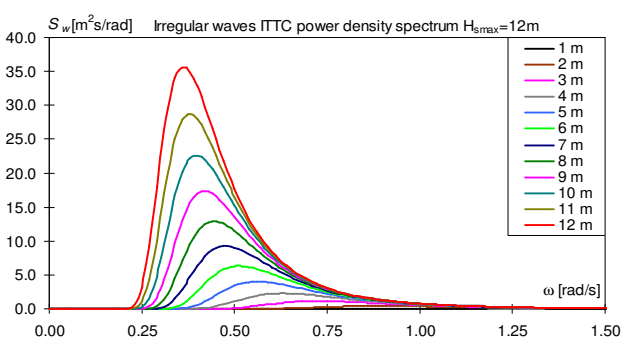

Fig.9. ITTC wave power density spectrum $S_{w}$ [10]

\subsection{Loading case TK1}

A selection of the statistic short-term results for the loading case TK1 (cargo) are included:

-Fig.10.a presents the $H_{\text {slimit }}$ for $v=15 \mathrm{kn}$, $z_{G}=8-14 \mathrm{~m}$, criteria A (Table 3) and Fig.10.b for $v=0-15 \mathrm{kn}, z_{G}=8-14 \mathrm{~m}$, at beam sea;

-Figs.11.a,b present the most probable amplitudes for roll, $v=0 \mathrm{kn}, z_{G}=8-14 \mathrm{~m}$, at beam sea; -Figs.12.a,b present the $H_{\text {slimit }}$ and $B_{\text {limit }}$ for $v=0-15 \mathrm{kn}, z_{G}=12 \mathrm{~m}$, criteria A (Table 3);

-Figs.12.c,d present the lower $H_{\text {slimit }}$ and heading angle, $v=0-15 \mathrm{kn}, z_{G}=8-14 \mathrm{~m}$, criteria A; -Fig. 13 presents the $H_{\text {slimit }}$ for $v=0-15 \mathrm{kn}$, $z_{G}=12 \mathrm{~m}$, criteria B (Table 3 );

-Tables 4.a,b present the $H_{\text {slimit }}$ and $B_{\text {limit }}$ for $v=0-15 \mathrm{kn}, z_{G}=8-14 \mathrm{~m}$, criteria A and B.

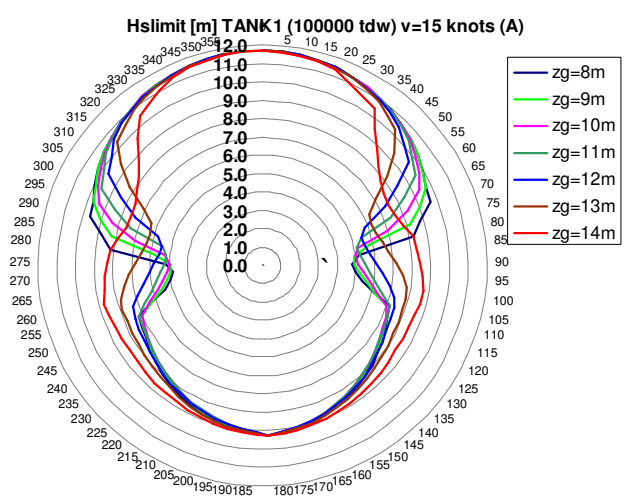

Fig.10.a. $H_{\text {slimit }}[\mathrm{m}](\mathrm{A}), \mathrm{TK} 1, v=15 \mathrm{kn}, z_{G}=8-14 \mathrm{~m}$

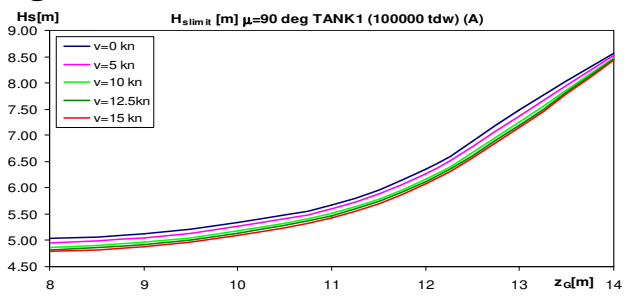

Fig.10.b. $H_{\text {slimit }}[\mathrm{m}](\mathrm{A}), \mathrm{TK} 1, \nu=0-15 \mathrm{kn}, \mu=90 \mathrm{deg}$ 


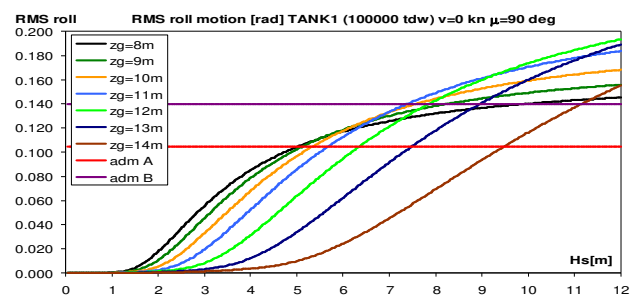

Fig.11.a. $R M S_{4}[\mathrm{rad}], \mathrm{TK} 1, v=0 \mathrm{kn}, \mu=90 \mathrm{deg}$

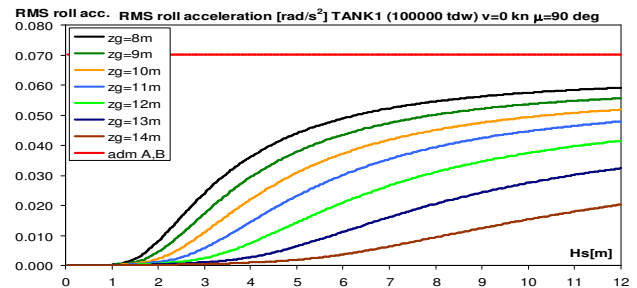

Fig.11.b. $R M S a c_{4}\left[\mathrm{rad} / \mathrm{s}^{2}\right], \mathrm{TK} 1, v=0 \mathrm{kn}, \mu=90 \mathrm{deg}$

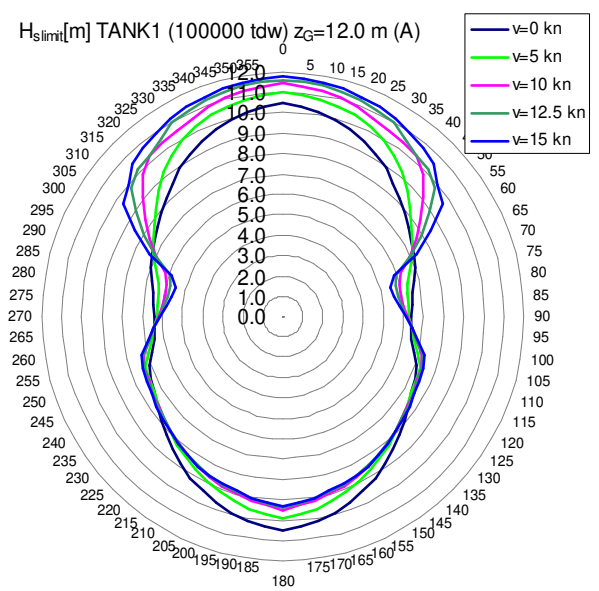

Fig.12.a. $H_{\text {slimit }}[\mathrm{m}](\mathrm{A}), \mathrm{TK} 1, v=0-15 \mathrm{kn}, z_{G}=12 \mathrm{~m}$

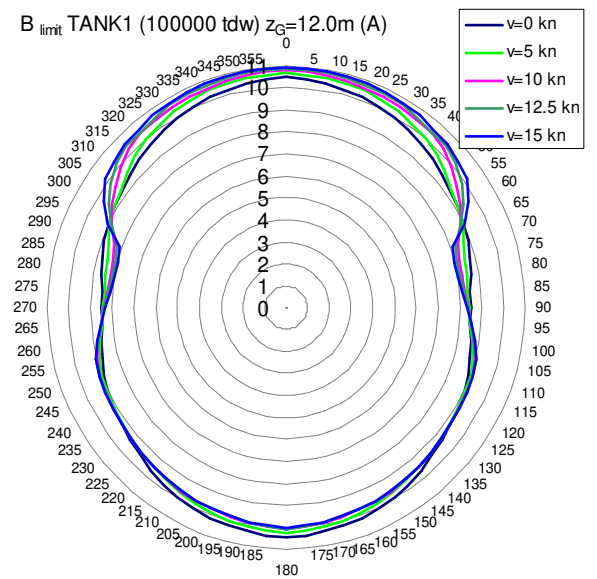

Fig.12.b. $B_{\text {limit }}(\mathrm{A}), \mathrm{TK} 1, \nu=0-15 \mathrm{kn}, z_{G}=12 \mathrm{~m}$

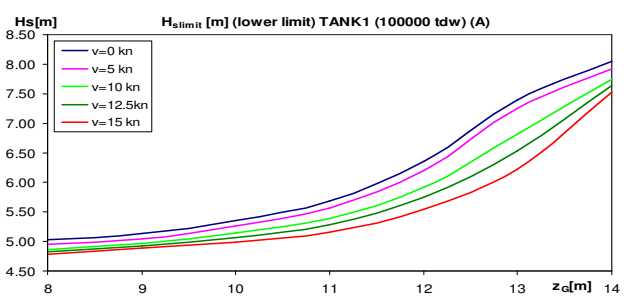

Fig.12.c. $H_{\text {slimit }}[\mathrm{m}](\mathrm{A})$ lower, TK1, $v=0-15 \mathrm{kn}$

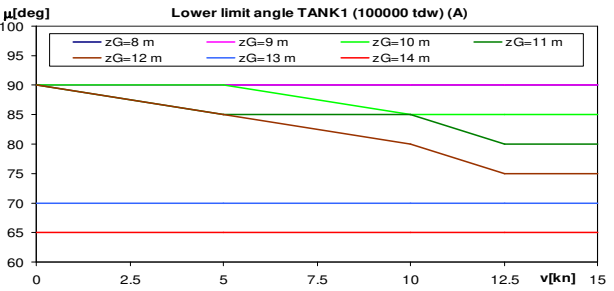

Fig.12.d.Lower limit angle (A), $\mathrm{TK} 1, z_{G}=8-14 \mathrm{~m}$

Table.4.a. $H_{\text {slimit }}[\mathrm{m}], \mathrm{B}_{\text {limit }}(\mathrm{A}), \mathrm{TK} 1, d_{m}=15 \mathrm{~m}$ \begin{tabular}{|c|c|c|c|c|}
\hline$v[\mathrm{kn}]$ & $z_{G}[\mathrm{~m}]$ & $H_{\text {slimit }}[\mathrm{m}]$ & $B_{\text {limit }}$ & Criterion \\
\hline
\end{tabular}

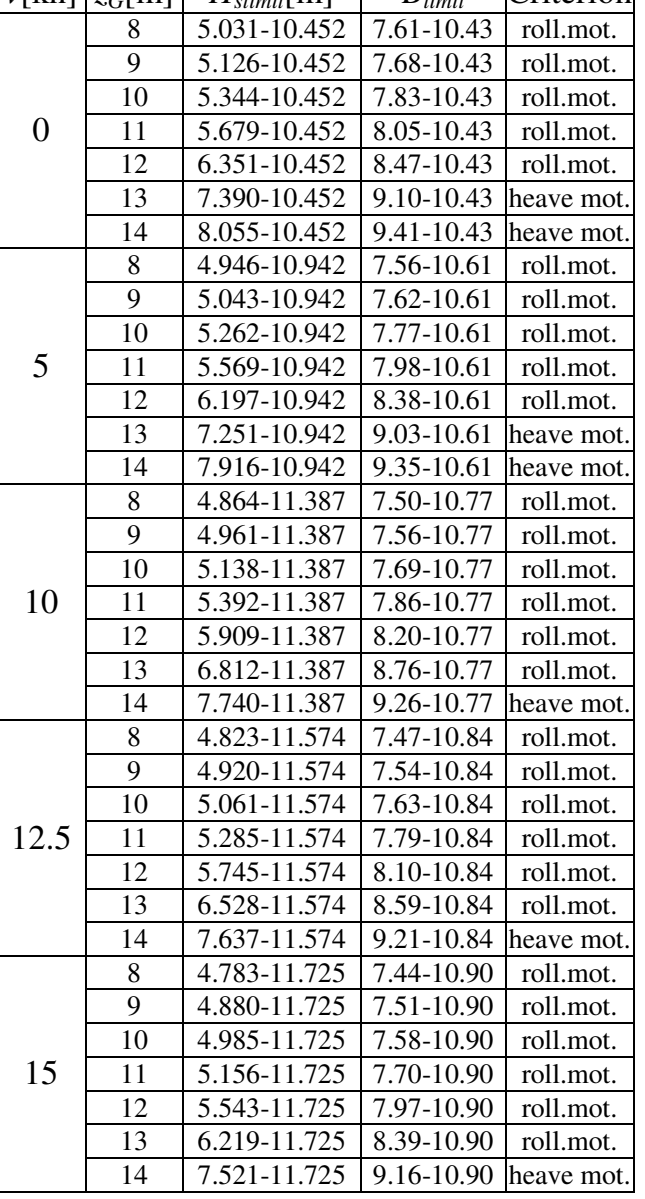




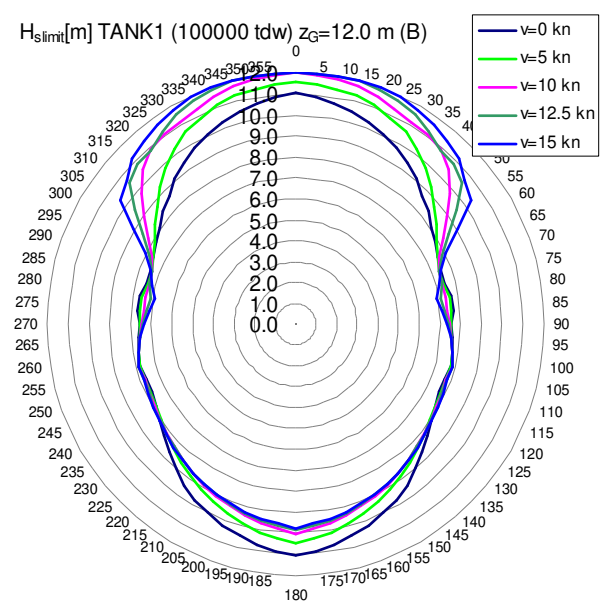

Fig.13. $H_{\text {slimit }}[\mathrm{m}](\mathrm{B}), \mathrm{TK} 1, v=0-15 \mathrm{kn}, z_{G}=12 \mathrm{~m}$

Table.4.b. $H_{s l i m i t}[\mathrm{~m}], \mathrm{B}_{\text {limit }}(\mathrm{B}), \mathrm{TK} 1, d_{m}=15 \mathrm{~m}$ \begin{tabular}{|c|c|c|c|c|}
\hline$v[\mathrm{kn}]$ & $z_{G}[\mathrm{~m}]$ & $H_{\text {slimit }}[\mathrm{m}]$ & $B_{\text {limit }}$ & Criterion \\
\hline & & &
\end{tabular}

\begin{tabular}{|c|c|c|c|c|}
\hline \multirow{5}{*}{0} & 8 & $7.666-11.045$ & $9.23-10.65$ & heave mot. \\
\cline { 2 - 5 } & 9 & $7.496-11.045$ & $9.15-10.65$ & heave mot. \\
\cline { 2 - 5 } & 10 & $7.375-11.045$ & $9.09-10.65$ & heave mot. \\
\cline { 2 - 5 } & 11 & $7.325-11.045$ & $9.06-10.65$ & heave mot. \\
\cline { 2 - 5 } & 12 & $7.458-11.045$ & $9.13-10.65$ & heave mot. \\
\cline { 2 - 5 } & 13 & $7.790-11.045$ & $9.29-10.65$ & heave mot. \\
\cline { 2 - 5 } & 14 & $8.467-11.045$ & $9.61-10.65$ & heave mot. \\
\hline \multirow{5}{*}{15} & 8 & $7.469-12.000$ & $9.13-11.00$ & heave mot. \\
\cline { 2 - 5 } & 9 & $7.340-12.000$ & $9.07-11.00$ & heave mot. \\
\cline { 2 - 5 } & 10 & $6.943-12.000$ & $8.85-11.00$ & roll.mot. \\
\cline { 2 - 5 } & 11 & $6.716-12.000$ & $8.70-11.00$ & roll.mot. \\
\cline { 2 - 5 } & 12 & $6.948-12.000$ & $8.85-11.00$ & roll.mot. \\
\cline { 2 - 5 } & 13 & $7.349-12.000$ & $9.08-11.00$ & heave mot. \\
\cline { 2 - 5 } & 14 & $7.921-12.000$ & $9.35-11.00$ & heave mot. \\
\hline
\end{tabular}

\subsection{Loading case TK2}

A selection of the statistic short-term results for the loading case TK2 (ballast) are included: -Fig.14.a presents the $H_{\text {slimit }}$ for $v=15 \mathrm{kn}$, $z_{G}=8-14 \mathrm{~m}$, criteria A (Table 3) and Fig.14.b for $v=0-15 \mathrm{kn}, z_{G}=8-14 \mathrm{~m}$, at beam sea;

-Figs.15.a,b present the most probable amplitudes for roll motion and acceleration, $v=0 \mathrm{kn}, z_{G}=8-14 \mathrm{~m}$, at beam sea;

-Figs.16.a,b present the $H_{\text {slimit }}$ and $B_{\text {limit }}$ for $v=0-15 \mathrm{kn}, z_{G}=10 \mathrm{~m}$, criteria A (Table 3 );

-Fig.16.c presents the lower $H_{\text {slimit }}$ for $\mathrm{v}=0$ $15 \mathrm{kn}, z_{G}=8-14 \mathrm{~m}$, criteria A (Table 3);

-Fig. 17 presents the $H_{\text {slimit }}$ for $v=0-15 \mathrm{kn}$, $z_{G}=10 \mathrm{~m}$, criteria B (Table 3);

-Tables 5.a,b present the $H_{\text {slimit }}$ and $B_{\text {limit }}$ for $v=0-15 \mathrm{kn}, z_{G}=8-14 \mathrm{~m}$, criteria A and B.

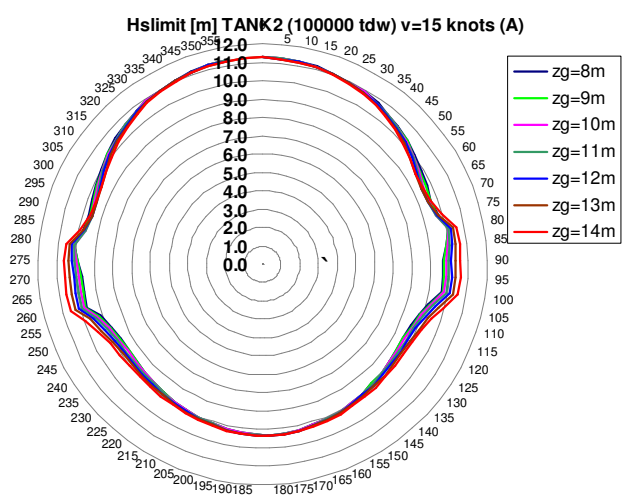

Fig.14.a. $H_{\text {slimit }}[\mathrm{m}](\mathrm{A}), \mathrm{TK} 2, v=15 \mathrm{kn}, z_{G}=8-14 \mathrm{~m}$

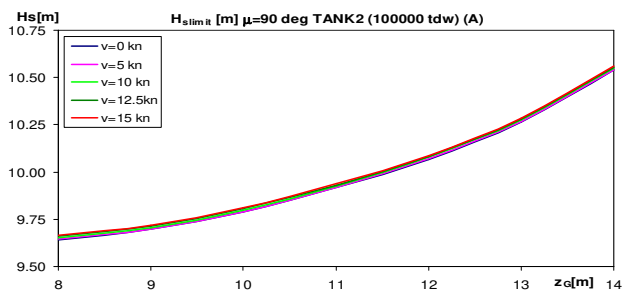

Fig.14.b. $H_{\text {slimit }}[\mathrm{m}](\mathrm{A}), \mathrm{TK} 2, v=0-15 \mathrm{kn}, \mu=90 \mathrm{deg}$

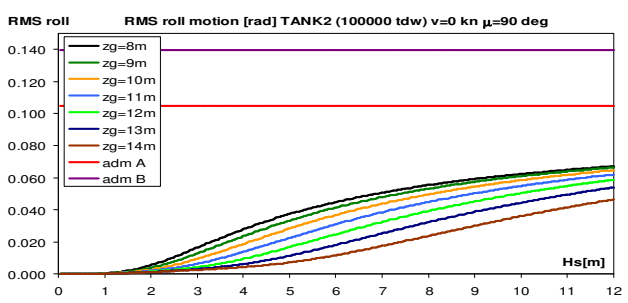

Fig.15.a. $R M S_{4}[\mathrm{rad}], \mathrm{TK} 2, v=0 \mathrm{kn}, \mu=90 \mathrm{deg}$

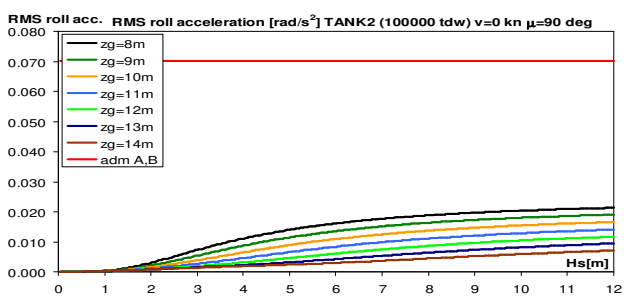

Fig.15.b. $R M S a c_{4}\left[\mathrm{rad} / \mathrm{s}^{2}\right], \mathrm{TK} 2, v=0 \mathrm{kn}, \mu=90 \mathrm{deg}$

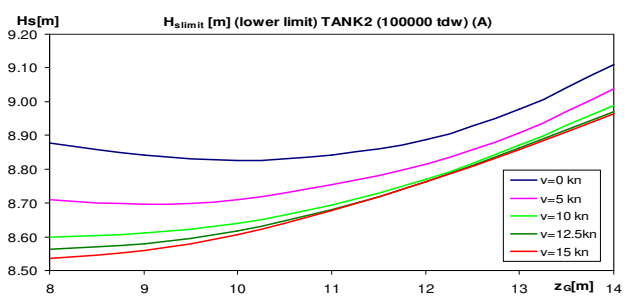

Fig.16.c. $H_{\text {slimit }}[\mathrm{m}](\mathrm{A})$ lower, $\mathrm{TK} 2, v=0-15 \mathrm{kn}$ 


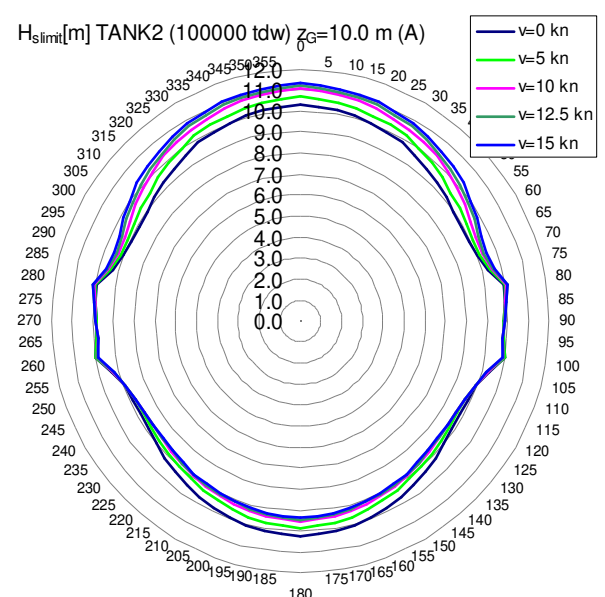

Fig.16.a. $H_{\text {slimit }}[\mathrm{m}](\mathrm{A}), \mathrm{TK} 2, v=0-15 \mathrm{kn}, z_{G}=10 \mathrm{~m}$

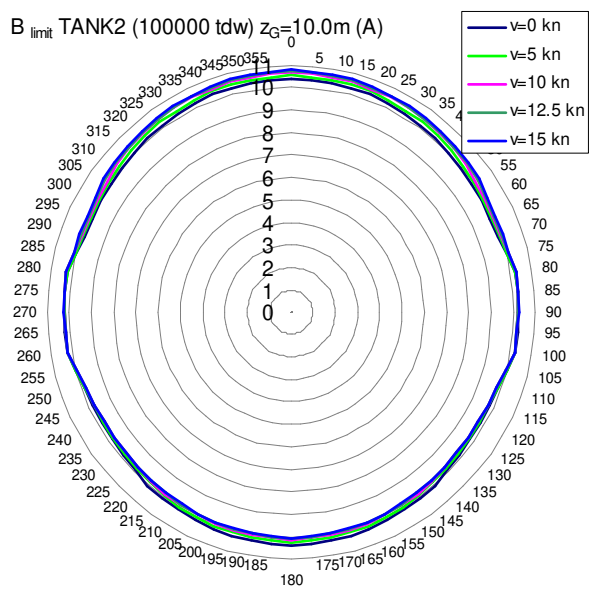

Fig.16.b. $B_{\text {limit }}(\mathrm{A}), \mathrm{TK} 2, v=0-15 \mathrm{kn}, z_{G}=10 \mathrm{~m}$

Table.5.a. $H_{\text {slimit }}[\mathrm{m}], \mathrm{B}_{\text {limit }}(\mathrm{A}), \mathrm{TK} 2, d_{m}=10 \mathrm{~m}$

\begin{tabular}{|c|c|c|c|c|}
\hline$v[\mathrm{kn}]$ & $z_{G}[\mathrm{~m}]$ & $H_{\text {slimit }}[\mathrm{m}]$ & $B_{\text {limit }}$ & Criterion \\
\hline \multirow{5}{*}{0} & 8 & $8.879-10.259$ & $9.81-10.36$ & heave mot. \\
\cline { 2 - 5 } & 9 & $8.843-10.259$ & $9.79-10.36$ & heave mot. \\
\cline { 2 - 5 } & 10 & $8.826-10.259$ & $9.78-10.36$ & heave mot. \\
\cline { 2 - 5 } & 11 & $8.842-10.259$ & $9.79-10.36$ & heave mot. \\
\cline { 2 - 5 } & 12 & $8.888-10.259$ & $9.81-10.36$ & heave mot. \\
\cline { 2 - 5 } & 13 & $8.977-10.361$ & $9.85-10.40$ & heave mot. \\
\cline { 2 - 5 } 5 & 14 & $9.111-10.601$ & $9.92-10.48$ & heave mot. \\
\hline \multirow{5}{*}{5} & 8 & $8.709-10.654$ & $9.73-10.50$ & heave mot. \\
\cline { 2 - 6 } & 9 & $8.695-10.654$ & $9.72-10.50$ & heave mot. \\
\cline { 2 - 6 } & 10 & $8.709-10.654$ & $9.73-10.50$ & heave mot. \\
\cline { 2 - 6 } & 11 & $8.755-10.654$ & $9.75-10.50$ & heave mot. \\
\cline { 2 - 6 } & 12 & $8.816-10.654$ & $9.78-10.50$ & heave mot. \\
\cline { 2 - 6 } & 13 & $8.907-10.654$ & $9.82-10.50$ & heave mot. \\
\cline { 2 - 5 } & 14 & $9.038-10.654$ & $9.88-10.50$ & heave mot. \\
\hline
\end{tabular}

\begin{tabular}{|c|c|c|c|c|}
\hline \multirow{5}{*}{10} & 8 & $8.599-11.014$ & $9.67-10.64$ & heave mot. \\
\cline { 2 - 5 } & 9 & $8.609-11.014$ & $9.68-10.64$ & heave mot. \\
\cline { 2 - 5 } & 10 & $8.640-11.014$ & $9.69-10.64$ & heave mot. \\
\cline { 2 - 5 } & 11 & $8.694-11.014$ & $9.72-10.64$ & heave mot. \\
\cline { 2 - 5 } & 12 & $8.770-11.014$ & $9.75-10.64$ & heave mot. \\
\cline { 2 - 5 } & 13 & $8.871-11.014$ & $9.80-10.64$ & heave mot. \\
\cline { 2 - 5 } & 14 & $8.988-11.014$ & $9.86-10.64$ & heave mot. \\
\hline \multirow{5}{*}{12.5} & 8 & $8.564-11.164$ & $9.66-10.69$ & heave mot. \\
\cline { 2 - 5 } & 9 & $8.579-11.164$ & $9.66-10.69$ & heave mot. \\
\cline { 2 - 5 } & 10 & $8.617-11.164$ & $9.68-10.69$ & heave mot. \\
\cline { 2 - 5 } & 11 & $8.681-11.164$ & $9.71-10.69$ & heave mot. \\
\cline { 2 - 5 } & 12 & $8.763-11.164$ & $9.75-10.69$ & heave mot. \\
\cline { 2 - 5 } & 13 & $8.862-11.164$ & $9.80-10.69$ & heave mot. \\
\cline { 2 - 5 } & 14 & $8.971-11.164$ & $9.85-10.69$ & heave mot. \\
\hline \multirow{5}{*}{15} & 8 & $8.537-11.280$ & $9.64-10.73$ & heave mot. \\
\cline { 2 - 5 } & 9 & $8.560-11.280$ & $9.65-10.73$ & heave mot. \\
\cline { 2 - 5 } & 10 & $8.607-11.280$ & $9.68-10.73$ & heave mot. \\
\cline { 2 - 5 } & 11 & $8.677-11.280$ & $9.71-10.73$ & heave mot. \\
\cline { 2 - 5 } & 12 & $8.763-11.280$ & $9.75-10.73$ & heave mot. \\
\cline { 2 - 5 } & 13 & $8.858-11.280$ & $9.80-10.73$ & heave mot. \\
\cline { 2 - 5 } & 14 & $8.964-11.280$ & $9.85-10.73$ & heave mot. \\
\cline { 2 - 5 } & & & \\
\hline
\end{tabular}

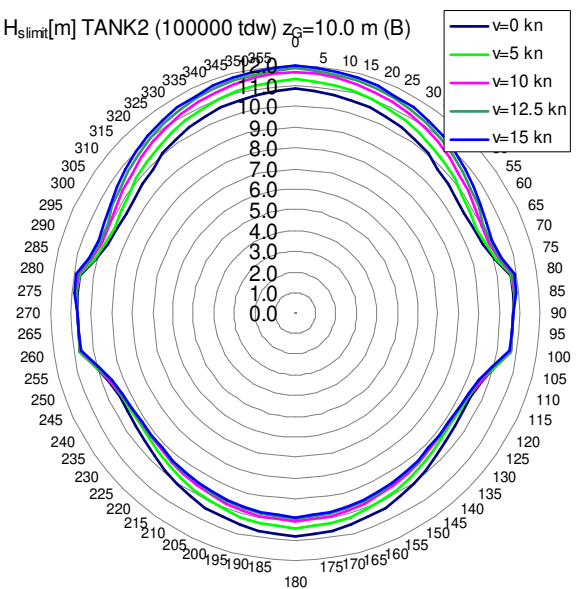

Fig.17. $H_{\text {slimit }}[\mathrm{m}](\mathrm{B}), \mathrm{TK} 2, v=0-15 \mathrm{kn}, z_{G}=10 \mathrm{~m}$

Table.5.b. $H_{\text {slimit }}[\mathrm{m}], \mathrm{B}_{\text {limit }}(\mathrm{B}), \mathrm{TK} 2, d_{m}=10 \mathrm{~m}$

\begin{tabular}{|c|c|c|c|c|}
\hline$v[\mathrm{kn}]$ & $z_{G}[\mathrm{~m}]$ & $H_{\text {slimit }}[\mathrm{m}]$ & $B_{\text {limit }}$ & Criterion \\
\hline \multirow{5}{*}{0} & 8 & $9.512-10.848$ & $10.08-10.58$ & heave mot. \\
\cline { 2 - 5 } & 9 & $9.463-10.848$ & $10.07-10.58$ & heave mot. \\
\cline { 2 - 5 } & 10 & $9.439-10.848$ & $10.06-10.58$ & heave mot. \\
\cline { 2 - 5 } & 11 & $9.447-10.848$ & $10.06-10.58$ & heave mot. \\
\cline { 2 - 5 } & 12 & $9.486-10.961$ & $10.07-10.62$ & heave mot. \\
\cline { 2 - 5 } & 13 & $9.567-11.137$ & $10.10-10.68$ & heave mot. \\
\cline { 2 - 5 } & 14 & $9.690-11.397$ & $10.15-10.78$ & heave mot. \\
\hline \multirow{5}{*}{} & 8 & $9.083-11.917$ & $9.90-10.97$ & heave mot. \\
\cline { 2 - 5 } & 9 & $9.101-11.917$ & $9.91-10.97$ & heave mot. \\
\cline { 2 - 5 } & 10 & $9.146-11.917$ & $9.93-10.97$ & heave mot. \\
\cline { 2 - 5 } & 11 & $9.215-11.917$ & $9.97-10.97$ & heave mot. \\
\cline { 2 - 5 } & 12 & $9.291-11.917$ & $10.00-10.97$ & heave mot. \\
\cline { 2 - 5 } & 13 & $9.385-11.917$ & $10.04-10.97$ & heave mot. \\
\cline { 2 - 5 } & 14 & $9.496-11.917$ & $10.08-10.97$ & heave mot. \\
\hline
\end{tabular}




\section{CONCLUSIONS}

For a 100000 tdw tanker [8] (Fig.1,Tables $1,2)$, based on our own code DYN [6], with theoretical model (1)-(6), a parametric study has been developed $\left(\Delta, z_{G}, v, \mu, H_{s}\right)$ for the dynamic response in regular and irregular waves, resulting the operation capabilities limits (7), by seakeeping criteria (8)-(11) (Table 3).

From the regular wave's dynamic response (for 2590 cases), the response amplitude operators are obtained (Figs.3-8). The heave $\mathrm{RAO}_{3}$ is maximal at quarter-head wave for TK1 and at beam wave for TK2. The pitch $\mathrm{RAO}_{5}$ is maximal at head waves for both loading cases, and is much reduced at beam waves. The roll $\mathrm{RAO}_{4}$ is maximal at beam waves, with zero values at follow and head waves.

For reference $v=0 \mathrm{kn}, \mu=90 \mathrm{deg}$. (Figs. 5.d, 8.d.), the maximum roll $\mathrm{RAO}_{4}$ is for $z_{G}=8 \mathrm{~m}$ and decreases for $z_{G}=9-14 \mathrm{~m}$, due to the increase of the hydrodynamic damping, while the natural period increase (Tables 2.a,b). The ship's speed influence is reduced at beam waves, being significant on the other heading angles.

From the irregular wave's dynamic response, in 621600 cases, the short-term most probable amplitudes $R M S$ and the operation limits in terms of polar diagrams $H_{\text {slimit }}, B_{\text {limit }}$ are obtained (Figs.10-17, Tables 4,5). The main restriction criteria are heave (9) and roll (10) motions for TK1 and only heave motion for TK2. The influence of the $z_{G}=8-14 \mathrm{~m}$ over the roll $R M S_{4}, \quad R M S_{a c 4}$ is very significant (Figs.11,15), also affecting the vertical $R M S_{Z}$ (8). The $z_{G}$ influence on operation limits is mainly on beam and quarter sea (Figs.10,14).

The operation limits for criteria $\mathrm{A}$ are in the range: $H_{\text {slimil }}=4.783-11.725 \mathrm{~m} \quad\left(B_{\text {limil }}=7.44\right.$ $10.90)$ for TK1, $H_{\text {slimit }}=8.537-11.280 \mathrm{~m}\left(B_{\text {limit }}=\right.$ 9.64-10.73) for TK2. If the reduced criteria B (Table 3) are considered, the operation limits are improving: $H_{\text {slimii }}=7.469-12 \mathrm{~m}\left(B_{\text {limit }}=9.13\right.$ 11) for $\mathrm{TK} 1, H_{\text {slimit }}=9.083-11.917 \mathrm{~m}\left(B_{\text {limit }}=\right.$ 9.90-10.97) for TK2. A significant influence of the ship's speed and gravity centre position is recorded (Figs.12,13,16,17, Tables 4,5).

Further studies will extend this analysis on other ship types and loading conditions.

\section{Acknowledgements}

This study and the program DYN [6] are developed at the Naval Architecture Research Centre, from "Dunarea de Jos" University of Galati.

\section{REFERENCES}

[1]. Bertram, V, "Practical ship hydrodynamics", Butterworth Heinemann, Oxford, 2000.

[2]. Bidoae, I., Ionas, O., "Naval architecture complements", Porto-Franco, Galati, 1998.

[3]. Burlacu, E., Domnisoru, L., Obreja, D., "Seakeeping prediction of a survey vessel operating in the Caspian Sea", The $37^{\text {th }}$ International Conference on Offshore Mechanics and Arctic Engineering, ASME, Paper No. OMAE 2018-77126, Madrid, 2018.

[4]. BV, "Rules", Bureau Veritas, Paris, 2019.

[5]. DNV-GL, "Rules", Det Norske Vertias Germanischer Lloyd, 2019.

[6]. Domnisoru, L., "Ship dynamics. Oscillations and vibrations", Technical Publishing House, Bucharest 2001.

[7]. Domnisoru, L., Rubanenco, I., Obreja, D., "The experimental and numerical linear and non-linear analyses of oscillations response, based on a scaled ITTC type ship model", The Annals of "Dunarea de Jos" University of Galati, Fascicle XI Shipbuilding, pp.75-84, 2013.

[8]. Dumitru, D., "Compendium of ships forms", "Dunarea de Jos" University Foundation Publishing House, Galati, 2014.

[9]. Gasparotti, C., Domnisoru, L., Obreja, D., "The oscillations analysis in head waves of a tractor-tug model by experimental and numerical methods", $16^{\text {th }}$ SGEM GeoConference on Water Resources,(3), pp.877-884, Albena, 2016.

[10]. ITTC, "Recommended procedures and guidelines. Seakeeping”, The International Towing Tank Conference, 2011.

[11]. Obreja, D., "Ship theory. Concepts and methods for the navigation performances analysis", E.D.P. Publishing House, Bucharest, 2005.

[12]. Obreja, D., Nabergoj, R., Crudu, L., Domnisoru, L., "Seakeeping performance of a Mediterranean fishing vessel”, IMAM, Maritime Transportation and Harvesting of Sea Resources, pp.483-491, Lisbon, 2017.

[13]. Solas, "International convention for the safety of life at sea", IMO, 2014.

[14]. Voitkunski, Y.I., "Ship theory handbook", Sudostroenie, Sankt Petersburg, 1985.

Paper received on August $20^{\text {th }}$, 2019 